\title{
A New Biomimetic Model for the Active Site of Oxovanadium(IV)-Transferrins $-\left[\mathrm{OV}^{\mathrm{IV}}(\mathbf{t f})\right]$
}

\author{
Ademir Neves $^{\mathrm{a}}{ }^{*}$, Stela Maris de Moraes Romanowski ${ }^{\mathrm{b}}$, Ivo Vencato ${ }^{\mathrm{a}}$, and \\ Antonio Salvio Mangrich ${ }^{\mathrm{b}}$ \\ a Departamento de Química, Universidade Federal de Santa Catarina, \\ 88040-900 Florianópolis - SC, Brazil; \\ ${ }^{\mathrm{b}}$ Departamento de Química, Universidade Federal do Paraná, \\ 81531-970 Curitiba - PR, Brazil
}

Received: May 15, 1998

\begin{abstract}
Reportamos neste trabalho, a síntese, a estrutura cristalina e propriedades espectroscópicas do novo complexo [OV $\left.{ }^{\mathrm{IV}}(\mathrm{HBIMETEN})\right]$, [H3BIMETEN $=N, N^{\prime}$-(2-hidroxibenzil)- $N$-(1-metilimidazol-2-il-metil)- $N$ '-hidroxietil-etilenodiamina] como um exemplo de complexo $\mathrm{V}^{\mathrm{IV}} \mathrm{O}^{2+}$ o qual contém grupos 1-metilimidazol e fenolato coordenados simultaneamente ao centro metálico. Este composto apresenta propriedades espectrais (EPR e UV-Vis) similares àquelas observadas na $\left[\mathrm{OV}^{\mathrm{IV}}(\mathrm{tf})\right]$.
\end{abstract}

The synthesis, X-ray crystal structure, and spectroscopic properties of the new coordination compound $\left[\mathrm{OV}^{\mathrm{IV}}(\mathrm{HBIMETEN})\right],\left[\mathrm{H}_{3} \mathrm{BIMETEN}=N, N^{\prime}\right.$ - (2-hydroxybenzil) $-N$-(1-methylimidazole-2-yl-methyl)- $N$ '-hydroxyethil-ethylenediamine] are reported as $\mathrm{V}^{\mathrm{IV}} \mathrm{O}^{2+}$ complex example containing phenolate and 1-methylimidazole coordinated simultaneously to the metal center. The EPR and UV-Vis properties of the title compound are similar to those observed in $\left[\mathrm{OV}^{\mathrm{IV}}(\mathrm{tf})\right]$.

Keywords: $V^{2+}$ complex, crystal structure, EPR, vanadium transferrin

\section{Introduction}

Vanadium has an important role in many biological processes. Particularly it has been proposed that delivery of vanadium in higher organisms is performed by transfer$\operatorname{rin}^{1}$. Transferrins are glycoproteins whose primary function is to bind and transport iron, but they also coordinate a wide variety of other metals including vanadium. They are a single polypeptide chain with two homologous lobes, denominated $\mathrm{C}$ - and $\mathrm{N}$-terminal, each of which binds one metal ion ${ }^{2 \mathrm{a}}$. Despite the binding of iron(III)-transferrin has been established through crystallographic studies $\left(\mathrm{NO}_{3}\right.$ coordination and $\mathrm{CO}_{3}{ }^{2-}$ as synergistic anion $)^{3}$, the coordination environment around the vanadium centre in vanadium-transferrins is not yet entirely known. It is well known that in the $+3,+4$, and +5 oxidation states, vanadium binds tightly to transferrin ${ }^{4,5}$. In an attempt to gain insight into the biological roles of vanadium, many recent studies have focussed on the coordination chemistry of this metal, in the oxidation states $+3,+4$ and +5 , with biologically relevant ligands ${ }^{6,7}$. In the +4 oxidation state, a vanadyl complex structure with octahedral geometry having an $\mathrm{NO}_{3}$ equatorial coordination (one tyrosinate, one aspartate, one histidine and one monodentate carbonate) has been proposed recently for vanadium human lactoferrin ${ }^{5}$. The coordination of histidine trans to the $\mathrm{V}=\mathrm{O}$ bond has also been proposed $^{6}$. This work is a continuation of a wide research program for the preparation and characterization of vanadium complexes of bioinorganic interest ${ }^{7}$.

\section{Experimental}

\section{Abbreviations}

$\mathrm{H}_{3}$ BIMETEN, $\quad N, N^{\prime}$-bis-(2-hydroxybenzyl)- $N$-(2methylimidazole)- $N$ '-(2-hydroxyethyl)ethylenediamine; $\mathrm{H}_{2}$ BBIMEN, $N, N$ '-bis-(2-hydroxybenzyl)- $N, N^{\prime}$-(2-me- 
thylimidazole)ethylenediamine); $\mathrm{H}_{2} \mathrm{BBPEN}, N, N$ '-bis(hydroxybenzyl)- $N, N^{\prime}$-bis(pyridyl- methyl)ethylenediamine); HIMETEN, $N$-(2-methylimidazole)- $N$ '-(2-hydroxyethyl) ethylenediamine; $\left[\mathrm{OV}^{\mathrm{IV}}(\mathrm{tf})\right]$, vanadium(IV)-transferrin.

\section{Synthesis}

The ligand $\mathrm{H}_{3} \mathrm{BIMETEN}$ was prepared in good yield $(91.36 \%)$ by the condensation reaction of 1-methyl-2-imidazolecarboxyaldehyde ${ }^{8}$ with $N$-(2-hydroxyethyl)ethylenediamine, followed by reduction with $\mathrm{NaBH}_{4}$ and by alkylation of the diamine (HIMETEN) with 2-bromomethylphenyl acetate ${ }^{9}$, by the route in Scheme 1 . The complex $\left[\mathrm{OV}^{\mathrm{IV}}(\mathrm{HBIMETEN})\right]$ (1) was prepared by refluxing a methanolic solution of $\mathrm{VOSO}_{4} \cdot \mathrm{H}_{2} \mathrm{O}(0.163 \mathrm{~g}, 1 \mathrm{mmol})$ and $\mathrm{H}_{3}$ BIMETEN $(0.410 \mathrm{~g}, 1 \mathrm{mmol})$ with stirring for $1 \mathrm{~h}$. To the reaction was added $\mathrm{Et}_{3} \mathrm{~N}(1 \mathrm{~mL}, 7.18 \mathrm{mmol})$, to yield a violet precipitate $(0.32 \mathrm{~g}-67.37 \%)$. Anal. Calc. for $\mathrm{C}_{23} \mathrm{H}_{30} \mathrm{~N}_{4} \mathrm{O}_{5} \mathrm{~V}$ : C, 55.98; H, 6.08; N, 11.35. Found: C, $55.63 ; \mathrm{H}, 5.95 ; \mathrm{N}, 10.96 \%$. The precipitate was recrystallized in an acetonitrile-ethanol (1:1) solution at room temperature. After a few days crystals suitable for X-ray crystallography were filtered off, washed with 2-propanol and dried with ether.

\section{$X$-ray crystallography}

Crystal data for $\mathrm{C}_{23} \mathrm{H}_{28} \mathrm{~N}_{4} \mathrm{O}_{4} \mathrm{~V}$. $1 / 2 \mathrm{C}_{2} \mathrm{H}_{5} \mathrm{OH}, \mathrm{M}=$ 498.47, monoclinic, $\mathrm{P} 2{ }_{1} / \mathrm{c},\left(\mathrm{n}^{\mathrm{o}}-14\right), \mathrm{Z}=4, \mathrm{a}=15.304(3)$, b $=12.329(3), c=12.441(3) \AA, \beta=94.18(3)^{\circ}, \mathrm{V}=2341.2$ (9) $\AA^{3}, D_{c}=1.414 \mathrm{~g} \mathrm{~cm}^{-3}, \mathrm{~F}(000)=1048, \mu=0.465 \mathrm{~mm}^{-1}$ for Mo- $K_{\alpha}$ radiation $(\lambda=0.71073 \AA)$, crystal size 0.07 x 0.20 x $0.43 \mathrm{~mm}$. Nonius CAD4 diffractometer, $\mathrm{T}=293 \mathrm{~K}$. Measured reflections: 4108, with 2971 unique reflections of which 1921 had $\mathrm{I}>2 \sigma(\mathrm{I})$. The structure was solved by direct methods, full-matrix refinement on $\mathrm{F}^{2}$, anisotropic refinement for all non-H atoms. One ethanol molecule was found to be disordered near an inversion center, with occu- pation factor of $1 / 2$. The number of refined parameters was $307, \mathrm{R} 1=0.0846, \mathrm{wR} 2=0.2465$. Crystallographic calculations were performed using the MOLEN, SHELXS97, SHELXL97 and ZORTEP computer program packages ${ }^{10}$.

\section{Results and Discussion}

The structure and atomic numbering scheme of 1 are illustrated in Fig. 1. The vanadium (IV) ion lies in a distorted octahedral environment, in which two phenolate oxygen, one amine and one imidazole nitrogen atoms in cis positions form the equatorial plane. The other amine nitrogen atom of the ethylenediamine backbone, in the transposition with respect to the terminal oxo group, and that oxo atom completes the coordination sphere of the vanadium center while the hydroxyl group remains uncoordinated. The VO distance is short [1.610(6) $\AA$ ], indicating the double bond character typical of vanadyl (IV) complexes $^{7 \mathrm{c}, \mathrm{d}, \mathrm{e}, \mathrm{f}}$. This value is slightly longer compared to that $[1.590(1) \AA]$ in $\left[\mathrm{OV}^{\mathrm{IV}}(\mathrm{HBBIMEN}]^{+}{ }^{7 \mathrm{e}}\right.$. As expected, the $\mathrm{V}-\mathrm{N}_{\text {(amine) }}$ bond distance of 2.372(6) $\AA$ trans to the $\mathrm{V}=\mathrm{O}$ bond in 1 , is $0.157 \AA$ longer than the $\mathrm{V}-\mathrm{N}_{(\text {amine) }}$ bond in the equatorial plane and is a consequence of the strong trans influence of the oxo group. The $\mathrm{V}-\mathrm{O}_{\text {(phenolate) }}[1.949(6)$ and 1.931(6) $\AA$ ] bond distances in 1 are longer than that detected in $\left[\mathrm{OV}^{\mathrm{IV}}(\mathrm{HBBIMEN}]^{+}[1.905(8) \AA]\right.$ due to a higher electronic density on the vanadium center in $1-\mathrm{N}_{3} \mathrm{O}_{3}$ coordination compared to $\left[\mathrm{OV}^{\mathrm{IV}}(\mathrm{HBBIMEN})^{+}-\mathrm{N}_{4} \mathrm{O}_{2}\right.$ coordination. The $\mathrm{V}-\mathrm{N}_{\text {(imidazole) }}[2.120(7) \AA]$ bond distance in the equatorial plane of 1 is $0.040(8) \AA$ longer than those found in $\left[\mathrm{OV}^{\mathrm{IV}}(\mathrm{HBBIMEN})\right]^{+}$[av. 2.080(9) $\AA$ ] and is a reflection of the weak trans influence caused by the phenolate bond in 1 . The above results reveal that, at least to some extent, 1 is more distorted that $\left[\mathrm{OV}^{\mathrm{IV}}(\mathrm{HBBIMEN})\right]^{+}$.

The electronic spectra of $\mathbf{1}$ measured in DMF in the visible region reveals the following transitions at $\lambda_{\max } / \mathrm{nm}$ $\left(\varepsilon / \mathrm{dm}^{3} \mathrm{~mol}^{-1} \mathrm{~cm}^{-1}\right): 881$ (20.08), 538 (76.28) and 441
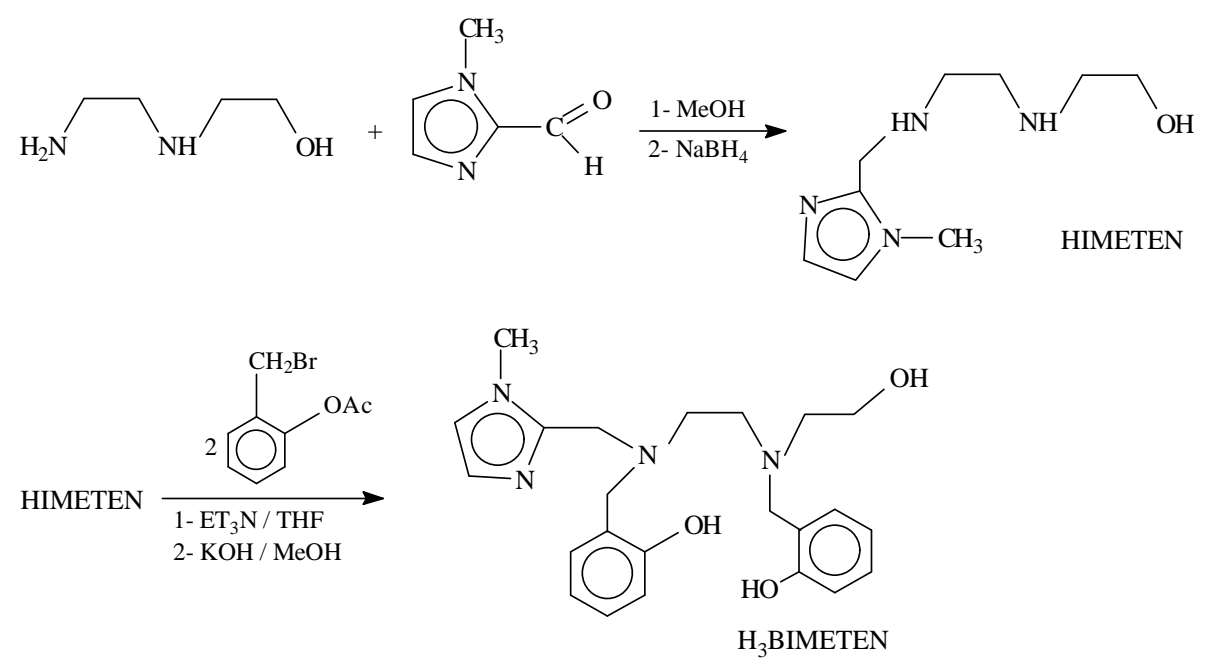

Scheme 1. Synthesis of the ligand $\mathrm{H}_{3} B I M E T E N$. 


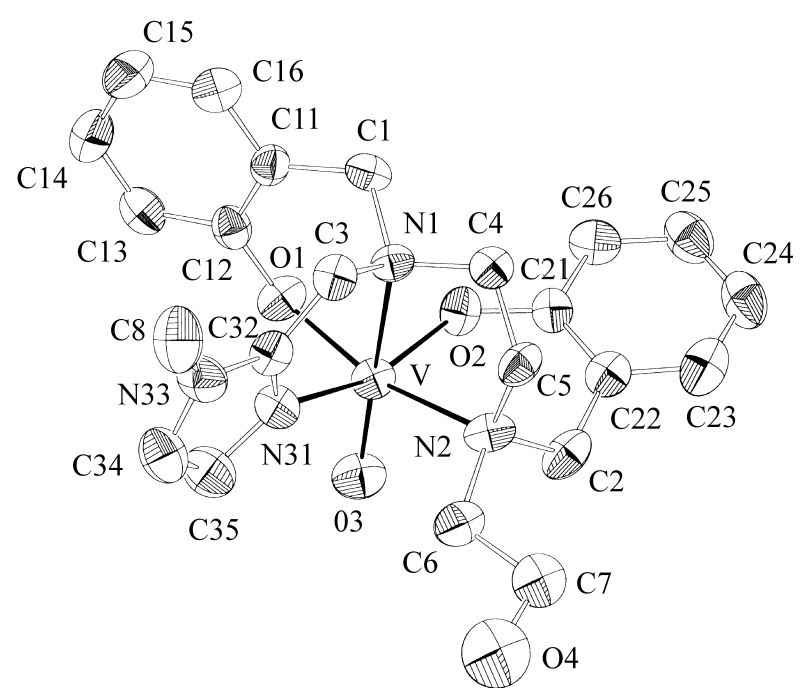

Figure 1. X-ray structure of 1 , showing the atom-labeling scheme, at $50 \%$ probability level. Selected bond lenghts $(\AA)$ and angles $\left(^{\circ}\right)$ : V-O3 1.610(6), V-O2 1.931(6), V-O1 1.949(6), V-N31 2.120(7), V-N2 2.215(7), V-N1 2.372(6), O3-V-O2 105.2(3), O3-V-O1 102.9(3), O2-V-O1 84.8(2), O3V-N31 95.7(3), O2-V-N31 158.9(3), O1-V-N31 88.3(2), O3-V-N2 93.7(3), O2-V-N2 88.6(2), O1-V-N2 163.2(3), N31-V-N2 92.5(3), O3-VN1 165.2(3), O2-V-N1 86.5(2), O1-V-N1 87.0(2), N31-V-N1 73.3(2), N2-V-N1 77.2(2) .

(100.78). According to Ballhausen and Gray ${ }^{11}$, the weak absorption at $881 \mathrm{~nm}$ is attributed to the d-d transition $d_{x y} \rightarrow d_{x z, y z}$ whereas those at 538 and $441 \mathrm{~nm}$ involve the $\mathrm{d}_{\mathrm{x}}{ }^{2}-\mathrm{y}^{2}$ and the $\mathrm{d}_{\mathrm{z}}{ }^{2}$ orbitals in compounds of $\mathrm{C}_{4 \mathrm{v}}$ symmetry, as in $\left[\mathrm{OV}^{\mathrm{IV}}(\mathrm{HBBIMEN})\right] \mathrm{PF}_{6}$ for which the corresponding transitions are observed at $\lambda_{\max } / \mathrm{nm}\left(\varepsilon / \mathrm{dm}^{3} \mathrm{~mol}^{-1} \mathrm{~cm}^{-1}\right): 826$ (46), 537 (76) and $380(462)^{12}$. In agreement with the X-ray crystal data previously described, $\mathbf{1}$ is a little more distorted than $\left[\mathrm{OV}^{\mathrm{IV}}(\mathrm{HBBIMEN})\right] \mathrm{PF}_{6}$ but not enough to split the $\mathrm{d}_{\mathrm{xy}} \rightarrow \mathrm{d}_{\mathrm{xz}, \mathrm{yz}}$ transitions as in $\left[\mathrm{OV}^{\mathrm{IV}}(\mathrm{tf})\right]^{4 \mathrm{~b}}$ and $\left[\mathrm{OV}^{\mathrm{IV}}\right.$ $(\mathrm{BBPEN})]^{7 \mathrm{c}}$.

The X-band EPR spectrum of a frozen solution of 1 in DMF together with the simulated spectrum is shown in Fig. 2. The Hamiltonian parameters obtained from the spectrum of $\mathbf{1}$, demonstrate the low symmetry geometric structure of the molecule, as can be observed in other vanadyl complexes previously reported in the literature ${ }^{2 \mathrm{~b}}$. The pseudoaxial (because the parameters $g_{x}$ and $g_{y}$ are very similar) distortion is in agreement with $\mathrm{X}$-ray diffraction data and the electronic absorption spectrum. However, this little in-plane observable anisotropy, $\left|\mathrm{g}_{\mathrm{x}}-\mathrm{g}_{\mathrm{y}}\right|=0.001$, $\left|\mathrm{a}_{\mathrm{x}}-\mathrm{a}_{\mathrm{y}}\right|=0.5 \times 10^{-4} \mathrm{~cm}^{-1}$, demonstrates that distortions in $\mathbf{1}$ are somewhat little more pronounced than those observed in $\left[\mathrm{OV}^{\mathrm{IV}}(\mathrm{HBBIMEN})\right]^{+}$, in which the in-plane anisotropy is not observable. The smaller values of the g parameters for an $\mathrm{N}_{2} \mathrm{O}_{2}$ equatorial coordination are consistent with the $\mathrm{d} \rightarrow \mathrm{d}$ transitions with lower energy found in $\mathbf{1}$, compared to the values observed in $\left[\mathrm{OV}^{\mathrm{IV}}(\mathrm{HBBIMEN})\right] \mathrm{PF}_{6}\left(\mathrm{~g}_{\mathrm{x}}=\mathrm{g}_{\mathrm{y}}\right.$ $\left.=1.9925, \mathrm{~g}_{\mathrm{z}}=1.9545\right)$ which has an $\mathrm{N}_{3} \mathrm{O}$ equatorial coor-

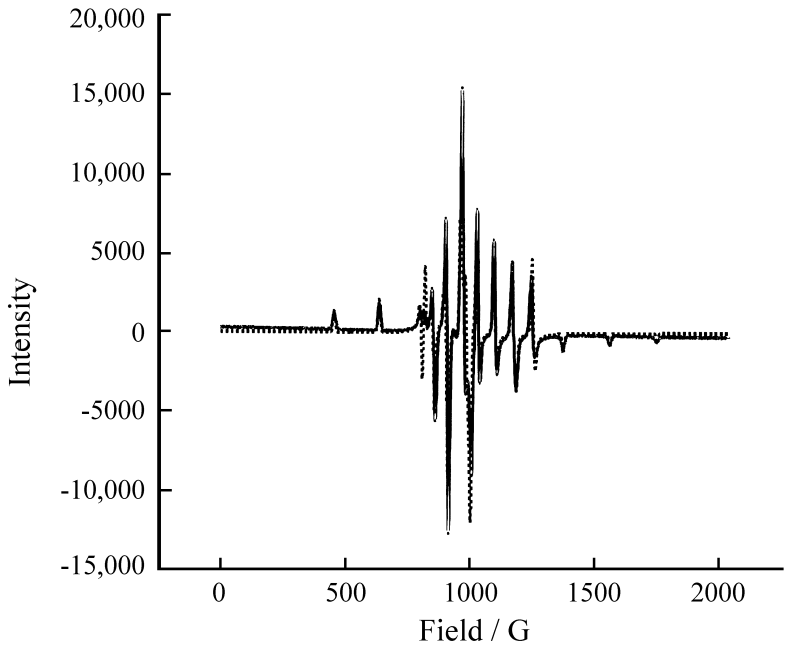

Figure 2. 2 X-band EPR spectrum of 1 in DMF at $77 \mathrm{~K}$. (xxx) Experimental spectrum and (-) simulated spectrum using the Winepr SimFonia Program, the molecular peak-peak linewidths referred to the $\mathrm{g}$ tensor axes of $\Delta \mathrm{B}_{\mathrm{x}}=9.00, \Delta \mathrm{B}_{\mathrm{y}}=12.00, \Delta \mathrm{B}_{\mathrm{z}}=8.00 \mathrm{G}$ and a Gaussian line-shape function. The Hamiltonian parameters are $\mathrm{g}_{\mathrm{x}}=1.9799, \mathrm{~g}_{\mathrm{y}}=1.9789, \mathrm{~g}_{\mathrm{z}}=$ $1.9436, A_{x}=57.55, A_{y}=57.05$, and $A_{z}=164.50 \times 10^{-4} \mathrm{~cm}^{-1}$.

dination, and consequently higher energy $\mathrm{d} \rightarrow \mathrm{d}$ transitions. The corresponding parameters found in the ovotransfer$\operatorname{rin}^{2 \mathrm{c}}$, a member of the family of the transferrins found in the white of eggs, are $g_{z}=1.939, g_{x}=1.978, g_{y}=1.974, A_{z}$ $=163.9, A_{x}=52.3$ and $A_{y}=59.2 \times 10^{-4} \mathrm{~cm}^{-1}$.

In summary, a $\mathrm{V}^{\mathrm{IV}} \mathrm{O}^{2+}$ complex containing a novel polyfunctional ligand has been prepared and characterized structurally and spectroscopically. In spite of the numerous $\mathrm{VO}^{2+}$ complexes with nitrogen and oxygen donor atoms described in the literature ${ }^{6,7}$, neither of these species exhibit all the characteristic spectral (UV-VIS and EPR) and structural properties found in $[\mathrm{V}(\mathrm{tf})]^{2 \mathrm{~b}, 4 \mathrm{~b}}$. Recent studies on the transferrins ${ }^{5}$, show that the form of the bound vanadium(IV) ion is $\mathrm{VO}^{2+}$ (vanadyl). These studies also proposed that each vanadyl ion is coordinated to two tyrosine residues, one histidine residue, a monodentate carbonate ion and to an aspartic acid. The EPR and UV-Vis spectral properties of the coordination compound $\left[\mathrm{O}=\mathrm{V}^{\mathrm{IV}}\right.$ (HBIMETEN)] described here, are very similar to those found in the ovotransferrin ${ }^{2 \mathrm{c}}$, therefore we can propose that $\mathbf{1}$ is a very interesting model for the $\left[\mathrm{OV}^{\mathrm{IV}}(\mathrm{tf})\right]$ complex.

\section{Acknowledgements}

This work was supported by grants from PRONEX, CNPq, FINEP, and PADCT.

\section{References}

1. Rehder, D. Angew. Chem., Int. Ed. Engl. 1991, 30, 148.

2. a) Chasteen, N.D. In Metal ions in biological systems, Sigel,H., ed., 1995, v. 31, p. 231. b) Chasteen, N.D. In Biological Magnetic Resonance, Berliner, L.; and 
Reuben, J., eds., Plenum: NY, 1981, v. 3, p. 53. c) Casey, J.D.; Chasteen, N.D. J. Inorg. Biochem. 1980, 13, 111.

3. Baker, E.N.; Anderson, B.F.; Baker, H.M.; Haridas, M.; Norris, G.E.; Rumball, S.V.; Smith, C.A. Pure and Appl. Chem. 1990, 62(6), 1067.

4. a) Bertini, I.; Canti, G.; Luchinat, C. Inorg. Chim. Acta 1982, 67 : L21-L23. b) Bertini, I.; Luchinat, C.; Messori, L. J. Inorg. Biochem. 1985, 25, 57.

5. Smith, C.A.; Ainscough, E.W.; Brodie, A.M. J. Chem. Soc., Dalton Trans. 1995, 1121.

6. a) Bonadies, J.A.; Carrano, C.J. J. Am. Soc. 1986, 108, 4088. b) Bonadies, J.A.; Butler, W.R.; Pecoraro, V.L.; Carrano, C.J. Inorg. Chem. 1987, 26, 1218. c) Li, X.; Lah, M.S.; Pecoraro, V.L. Inorg. Chem. 1988, 27, 4657. d) Colpas, G.J.; Hamstra, B.J.; Kampf, J.W.; Pecoraro, V.L. Inorg. Chem. 1994, 33, 4669. e) Butler, A.; Carrano, C.J. Coord. Chem. Rev. 1991, 109(1), 61.

7. a) Neves, A.; Ceccato, A.S.; Erthal, S.M.D.; Vencato, I.; Nuber, B.; Weiss, J. Inorg. Chim. Acta 1991, 187, 119. b) Neves, A.; Ceccato, A.S.; Vencato, I.; Mascarenhas, Y.P.; Erasmus-Buhr, C. J. Chem. Soc., Chem. Commun. 1992, 8, 652. c) Neves, A.; Ceccato, A.S.; Erasmus-Buhr, C.; Gehring, S.; Haase, G.; Paulus, H.; Nascimento, O.R.; Batista, A.A. J. Chem.
Soc., Chem. Commun. 1993, 23, 1782. d) Neves, A.; Vencato, I.; Mascarenhas, Y.P. Acta Crys. 1994, C50, 1417. e) Neves, A.; Tamanini, M.; Correa, V.R.; Vencato, I. J. Braz. Chem. Soc.1997, 8(5), 519. f) Neves, A.; Romanowski, S.M. de M.; Vencato, I.; Mangrich, A.S. J. Chem. Soc., Dalton Trans 1998, 4, 617.

8. Oberhausen, K.J.; Richardson, J.F.; Buchanan, R.M.; Pierce, W. Inorg. Chim. Acta 1989, 159, 219.

9. Karlin, K.D.; Cohen, B.I.; Hayes, J.C.; Farooq, A.; Zubieta, J. J. Inorg. Chem. 1987, 26, 147.

10. a) Fair, C.K.; MOLEN An Interactive Intelligent System for Crystal Structure Analysis. Enraf-Nonius, Delft, The Netherlands 1990. b) Sheldrick, G.M. SHELXS-97. Program for the Solution of Crystal Structures. University of Göttingen, Germany 1990. c) Sheldrick, G.M. SHELXL-97. Program for the Refinement of Crystal Structures. University of Göttingen, Germany 1997. d) Zsolnai, L.; ZORTEP. An Interactive ORTEP Program. University of Heidelberg, Germany 1996.

11. Ballhausen, C.J.; Gray, H.B. Inorg. Chem. 1962, 25, 111.

12. Pereira, M.T. da C. Ms. Thesis, 1996, Universidade Federal de Santa Catarina, Brazil. 